\title{
Antiobesity Activity of Bauhinia purpurea Extract: Effect on Hormones and Lipid Profile in High Calorie Diet Induced Obese Rats
}

\author{
Tiruttani Kuppireddy Padmaja1, Parim Brahma Naidu1, \\ Ghali Eswara Naga Hanuma Kumar'1, Saravanan Ganapathy², Meriga Balaji ${ }^{*}$ \\ ${ }^{1}$ Department of Biochemistry, Sri Venkateswara University, Tirupati, India \\ ${ }^{2}$ Department of Biochemistry, Center for Biological Sciences, K.S.R. College of Arts \& Sciences, \\ Tiruchengode, India \\ Email: ${ }^{*}$ balaji.meriga@gmail.com
}

Received 30 July 2014; revised 31 August 2014; accepted 27 September 2014

Copyright @ 2014 by authors and Scientific Research Publishing Inc.

This work is licensed under the Creative Commons Attribution International License (CC BY).

http://creativecommons.org/licenses/by/4.0/

(c) (i) Open Access

\begin{abstract}
Obesity is well recognized as a global public health concern and the quest continues to explore natural product-based novel therapeutics. Bauhinia purpurea finds its place in traditional medicine as an effective anti-ulcer, antiplatelet, wound healing and hypolipidemic agent. The present study investigated the effects of ethanolic extract of Bauhinia purpurea (EEB) on the changes in body weight, lean mass, fat free mass, fat percent, tissue and plasma lipid profiles, plasma glucose, insulin and insulin resistance as well as on the activity of amylase, lipase, leptin and adiponectin levels in high caloric diet (HCD) induced obese rats. After induction of obesity with HCD, rats were administered orally with EEB $\left(100,200\right.$ and $\left.300 \mathrm{mg} \cdot \mathrm{kg}^{-1} \mathrm{BW}\right)$ or orlistat $\left(5 \mathrm{mg} \cdot \mathrm{kg}^{-1} \mathrm{BW}\right)$ once daily for 42 days. HCD substantially increased the body weight, fat free mass, fat percent, glucose, insulin resistance, tissue and plasma lipid profiles (Except HDL), leptin and the activities of amylase and lipase. EEB at a dose of $300 \mathrm{mg} \cdot \mathrm{kg}^{-1} \mathrm{BW}$ exerted its therapeutic effects similar to orlistat in decreasing body weight, insulin resistance, levels of glucose, leptin, plasma and tissue lipids, lipase and amylase but increasing HDL and adiponectin in HCD fed obese rats, which could be due to bioactive factors present in EEB, as revealed by LC-MS analysis. These findings suggest that EEB administration suppresses high-caloric-diet-induced obesity and it can be developed as a potential candidate for the treatment of obesity and associated complications.
\end{abstract}

*Corresponding author.

How to cite this paper: Padmaja, T.K., et al. (2014) Antiobesity Activity of Bauhinia purpurea Extract: Effect on Hormones and Lipid Profile in High Calorie Diet Induced Obese Rats. Advances in Bioscience and Biotechnology, 5, 861-873.

http://dx.doi.org/10.4236/abb.2014.511101 


\section{Keywords}

\section{Obesity, Leptin, Fat Free Mass, Dyslipidemia, Inslin Resistance}

\section{Introduction}

Obesity is a common health disorder of lipid and carbohydrate metabolism which results from excessive fat accumulation in adipose tissue, liver, skeletal muscle etc. (WHO 2011) [1]. The prevalence of obesity is escalating across the world cutting across age groups, sex and ethnicity. Obesity is one of the major contributors to morbid conditions like type-2 diabetes, hypertension, cardiovascular disorders, and non-alcoholic fatty liver metabolic syndrome [2] [3]. Though the etiology of obesity is diverse, the root cause is energy disparity: more calories consumed than expended. It is characterized by the unwarranted increase of adipose tissue which is regulated by caloric rich nutritional factors and genetics [4].

Along with lifestyle modifications, the pharmacological approach to weight management includes reduction of nutrient absorption, modulating lipogenesis-lypolysis, regulating adipose signals and appetite centers [5]. Although a few FDA-approved drugs like orlistat and sibutramine are available in the market, they are not preferred for long-time usage owing to considerable adverse effects. Epidemiological studies have recommended the utilization of natural product-based drugs to reduce the risk of obesity and associated complications [6]. Therefore, attempts are being made to develop plant-based safe and effective drugs to treat obesity.

Bauhinia purpurea, a member of Leguminosae, is native to India and Southern China. Almost all parts of the plant are used in traditional medicine for the treatment of various ailments like asthma, leprosy, piles, snake bite and liver complaints [7]-[8]. Besides this, its extracts have been found to have antifungal activity [9]. Various well-reported pharmacological activities of $B$. purpurea include anti-ulcer, antiplatelet, hypotensive and hypolipidemic actions [10]. A good number of phytoconstituents from $B$. purpurea have been reported in literature, in addition to bauhiniastatins [7]. However, there is scanty of literature pertaining to antiobesity effects of B. purpurea. Diet intervention study in rodents is a good model to evaluate the anti obesity efficacy of a durg/formulation. Rats fed on high calorie diet (HCD) develop dyslipidemia and obesity which bear close resemblance to human obesity [11].

Therefore, in the present study, we carried out LC-MS analysis to find out the possible bioactive compounds present in the ethanolic extract of Bauhinia purpurea (EEB) and investigated the protective effects of EEB on body weight, fat free mass, fat-\%, glucose, insulin resistance, tissue and plasma lipid profiles, leptin, adiponectin and the activities of amylase and lipase in HCD-fed obese rats and sought possible mechanisms of action.

\section{Materials and Methods}

\subsection{Chemicals}

Fasting blood glucose and insulin were measured by using kits procured from Stanbio Laboratory USA, BioMerieux, RCS, Lyon, France respectively. Orlistat (Cat No. 04139) was obtained from Sigma-Aldrich. All other reagents used in the experiments were of analytical grade and of the high purity.

\subsection{Collection and Extraction of Plant Material}

The bark of Bauhinia purpurea was collected from Seshachalam forests of Rayalaseema region, A.P., India. Its identity was authenticated by a taxonomist, department of Botany, S.V. University, Tirupati, voucher number 136, and a specimen has been preserved at the departmental herbarium. The bark of B. purpurea was shade dried, pulverized to a coarse powder and sequentially extracted with hexane, ethylacetate, ethanol and water. The respective filtrates obtained were evaporated to dryness in a rotary vacuum evaporator to obtain respective dry extracts. Based on preliminary studies and phytochemical analysis, ethanolic extract was selected for further studies.

\subsection{LC-ESI-MS/MS Analysis B. purpurea Ethanolic Extract}

LC-ESI-MS/MS analysis of ethanolic extract of B. purpurea was carried out on 6520 Accurate Q-TOF (Agilent 
Santa Clara, CA) mass spectrometer coupled to HPLC equipped with a UV-Vis detector. The column used was Zobax SB C18 rapid resolution, $4.6 \mathrm{~mm} \times 150 \mathrm{~mm}, 3.5 \mu \mathrm{m}$ particle size (Column-SL, Model G1316B). The conditions were; mobile phase consisted of binary mixture of solvent (A) formic acid (0.1\%) and $10 \mathrm{mM}$ ammonium phosphate, (B) acetonitrile $+0.1 \%$ formic acid; gradient (in solvent B) with linear gradient programme as follows: Starting from 95\% solvent A and 5\% solvent B increasing to 35\% solvent B over 12 min, then increased to $90 \%$ over $35 \mathrm{~min}$, back to $5 \%$ solvent B over $1 \mathrm{~min}$ and finally isocratic for $10 \mathrm{~min}$. The sample wavelength was set at $240-360 \mathrm{~nm}$. A sample injection volume of $10 \mu \mathrm{l}$ in methanol and a constant flow rate of $0.3 \mathrm{ml} / \mathrm{min}$ were used for the analysis of sample. The mass spectra were acquired with ESI source (Agilent Santa Clara, CA). Nitrogen was used as the sheath and auxiliary gas and helium was used as the collision gas. The ESI MS spectra were acquired in positive ion mode and a spray voltage of $4 \mathrm{kV}$ was employed. The temperature of the heated transfer capillary was $325^{\circ} \mathrm{C}$. The mass spectrometer was scanned from m/z 100 to 1200 in full scan mode, gas flow $10 \mathrm{~L} / \mathrm{min}$; Nebulizer 40 psi [2].

\subsection{Animals and Diets}

Male Sprague-Dawley rats, normal diet and high caloric diet were obtained from National Centre for Laboratory Animal Sciences (NCLAS), National Institute of Nutrition (NIN), Hyderabad, India. Normal diet contained pellet chow of standard composition containing all the recommended macro and micronutrients (56\% carbohydrate, $18.5 \%$ protein, $8 \%$ fat, $12 \%$ fiber and adequate levels of minerals and vitamins). HCD contained $29.5 \%$ beef tallow, $22.0 \%$ casein, $23.0 \%$ starch, $17.9 \%$ cellulose, $4.0 \%$ L-cystine, $0.3 \%$ choline chloride, $1.8 \%$ vitamin mixture (AIN-93 ViX) and 1.5\% salt mixture. During the course of the experimental period (20 weeks), rats were fed with either normal diet or freshly prepared HCD (15 g/rat/day) as mentioned below and water ad libetum. Experimental animals were maintained under standard laboratory conditions (temperature: $22^{\circ} \mathrm{C} \pm 2{ }^{\circ} \mathrm{C}$; humidity: $40 \%-60 \%)$. Rats initially weighing $180-200 \mathrm{~g}$ were randomly divided in to six groups of six each $(\mathrm{n}=6)$. After induction of obesity, to test the activity of EEB, rats were treated with different doses of EEB (100, 200, or $300 \mathrm{mg} \cdot \mathrm{kg}^{-1} \mathrm{BW}$ ), suspended in $0.5 \%$ carboxy methyl cellulose (CMC), for 42 days ( $15^{\text {th }}$ to $20^{\text {th }}$ week), using an intragastric tube. All experimental protocols were followed as per institutional animal ethical committee guidelines (Resolution No: 55/2012/(i)/a/CPCSEA/IAEC/SVU/MBJ, Dt: 08.07.2012).

\subsection{Experimental Design}

Group 1: Normal Diet Control (Normal Diet).

Group 2: High Caloric Diet Control (HCD).

Group 3: HCD + Orlistat (5 $\left.\mathrm{mg} \cdot \mathrm{kg}^{-1} \mathrm{BW}\right)$.

Group 4: HCD + EEB (100 $\left.\mathrm{mg} \cdot \mathrm{kg}^{-1} \mathrm{BW}\right)$.

Group 5: HCD+ EEB (200 mg $\left.\mathrm{kg}^{-1} \mathrm{BW}\right)$.

Group 6: HCD + EEB (300 mg $\left.\mathrm{kg}^{-1} \mathrm{BW}\right)$.

\subsection{Measurement of Body Weight}

Once in a week, the body weight of experimental animals was measured. The total amount of food consumed was recorded daily (data are not shown). At the end of the experiment, blood was collected from overnight fasted animals under inhalation of anaesthesia by retro-orbital puncture method. Plasma was separated by centrifugation at $2500 \mathrm{rpm}$ for $15 \mathrm{~min}$ and was used for further experiments.

\subsection{Body Composition}

Body composition of experimental animals was assessed at the end of experimental period by Total Body Electrical Conductivity (TOBEC) using small animal body composition analysis system (EM-SCAN, Model SA3000 Multi detector, Springfield, USA). Lean body mass, fat free mass and total body fat and fat percentage were calculated as described previously [11] [43].

\subsection{Blood Glucose, Insulin and Insulin Resistance}

At the end of the experiment, blood was collected from overnight fasted rats under inhalation of anaesthesia by 
retro-orbital puncture method. Plasma was separated by centrifugation at $2500 \mathrm{rpm}$ for $15 \mathrm{~min}$. Plasma glucose was estimated using kits (Cat No. 1060-500, Stanbio laboratory, USA). Plasma insulin was determined using kits obtained from Bio-Merieux, RCS, Lyon, France. Insulin resistance was calculated using the homeostasis model assessment [12].

\subsection{Oral Glucose Tolerance Test (OGTT)}

To test glucose tolerance, OGTT was performed. At the end of the experiment, after overnight fasting, glucose was administered orogastrically at a dose of $2.0 \mathrm{~g} \cdot \mathrm{kg}^{-1} \mathrm{BW}$ to rats and blood samples were collected from supra orbital sinus at $0,30,60$ and 120 minutes and glucose level was estimated.

\subsection{Estimation of Leptin and Adiponectin}

Plasma leptin and adiponectin levels were measured by using enzyme linked immunosorbent assay kits (Crystal Chem, Downer's Grove, IL, USA), performed in duplicate, as per the manufacturer's guidelines and were expressed in $\mathrm{ng} \cdot \mathrm{mL}^{-1}$.

\subsection{Estimation of Plasma Lipid Profiles}

For estimation of lipid profiles, blood samples were centrifuged at $4000 \mathrm{rpm} / \mathrm{min}$ for $10 \mathrm{~min}$ to separate plasma which was then stored at $-80^{\circ} \mathrm{C}$ for further biochemical analysis. Total cholesterol, HDL and triacylglyceride levels were estimated by CHOD-PAP method and GPO-PAP method [11]. LDL levels were calculated by the method of Johnson et al. (1997) [13].

\subsection{Estimation of Tissue Lipid Profiles}

Tissue lipids were extracted from experimental animals by the method of Floch et al. (1957) [14]. The liver tissues were rinsed with ice cold physiological saline, dried, homogenized in cold chloroform-methanol (2:1, v/v) and contents were extracted after $24 \mathrm{~h}$. The extraction was repeated four times. The combined filtrate was washed with $0.7 \% \mathrm{KCl}$ and the aqueous layer was discarded. The organic layer was made up to a known volume with chloroform and used for tissue lipid analysis.

\subsection{Estimation of Pancreatic Lipase and Amylase Activity}

Pancreatic lipase and amylase activities were determined by kinetic method using commercial kits (Bioclin ${ }^{\circledR}$, Minas Gerais, Brazil) following the guidelines of the manufacturer.

\subsection{Statistical Analysis}

All the results were expressed as the mean \pm S.D. for six animals in each group. All the grouped data were statistically evaluated with SPSS $\backslash 10.0$ software. Hypothesis testing methods included one way analysis of variance (ANOVA) followed by Least Significant Difference (LSD) test. Significance level at $p<0.05,0.01,0.001$ were considered to indicate statistical significance.

\section{Results}

\subsection{Phytochemical Analysis}

Phytochemical analysis of ethanolic extract of B. purpurea was carried out by LC-Q-TOF MS/MS to identify the compounds present in EEB. MS/MS spectra of the mass to charge ratio of ESI scanned spectra results are showed in Figure 1. The major compounds identified in EEB were 2,4'-Dihydroxy-4-methoxydihydrochalcone, Isoliquiritigenin 2'-methyl ether, 4'-Hydroxy-7,3'-dimethoxyflavan, 2,3-Dihydroxy propyl oleate, Bauhiniastatin-1, 5,7,3',4',5'-Pentamethoxyflavone, Preracemosol B and 5,7,3',4'-Tetramethoxyflavone. Among these, Bauhiniastatin-1 and 5,7,3',4'-Tetramethoxyflavone (Kaempferol) were found to be most abundant $(12.36 \%$ and $15.48 \%$ respectively). Remaining compounds were present in concentrations of less than $2 \%$. 


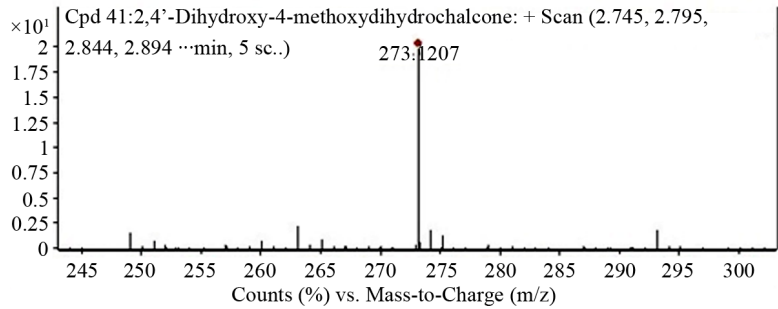

(a)

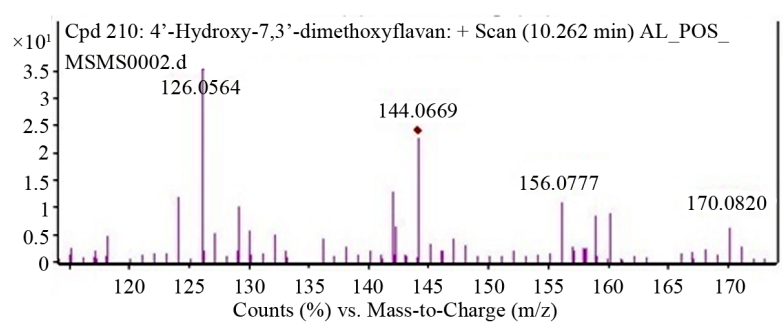

(c)

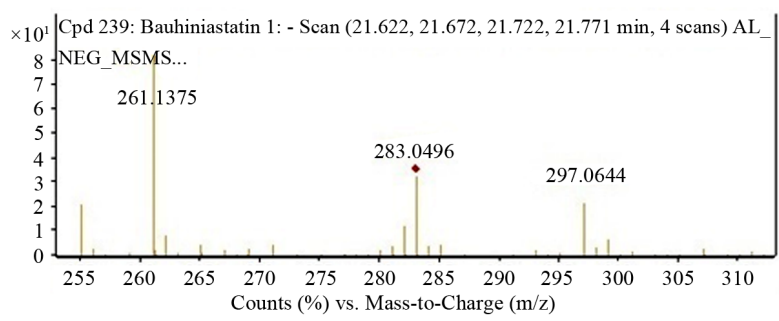

(e)

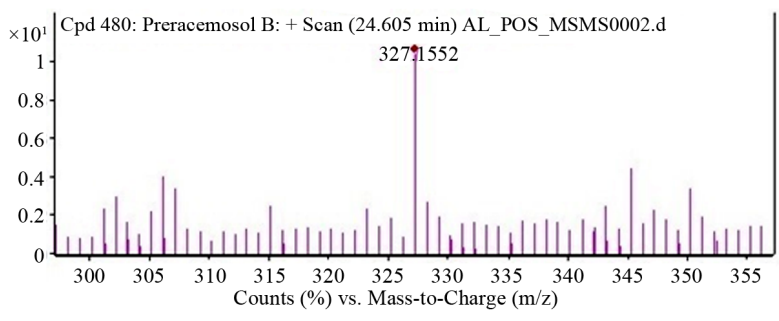

(g)

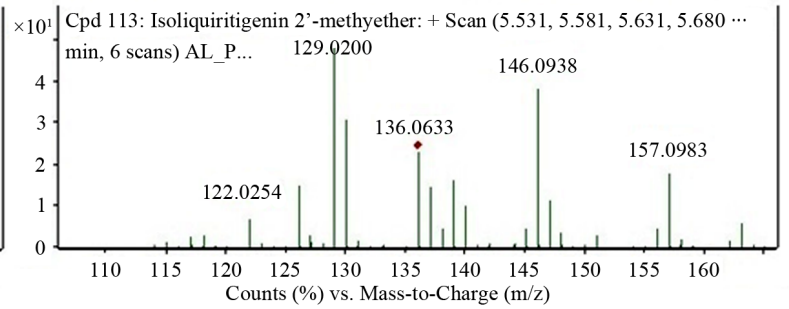

(b)

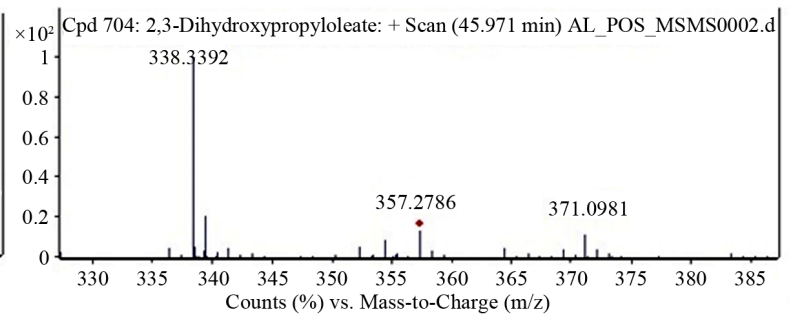

(d)

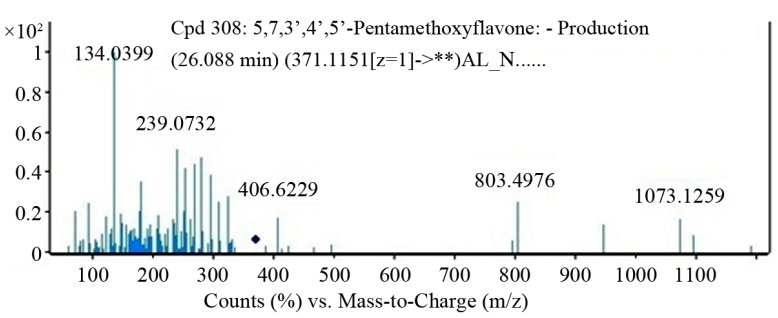

(f)

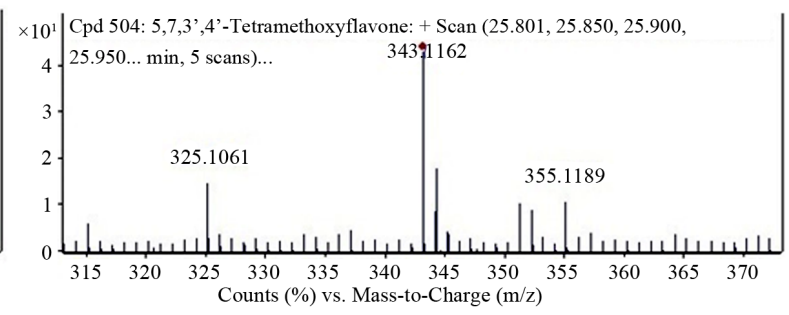

(h)

Figure 1. LC-MS analysis of ethanolic extract of Bauhinia purpurea.

\subsection{Body Weight and Body Composition}

Figure 2 depicts the changes in body weight and body composition of experimental rats. Consumption of HCD for 20 weeks produced a substantial increase in body weight (468 $\pm 8.3 \mathrm{~g})$, total fat $(75.9 \pm 9.4 \mathrm{~g})$, fat \% (16.1 \pm 3.8), and fat free mass (173.1 $\pm 2.8 \mathrm{~g})$ in HCD control group when compared to normal control group of rats whose body weight, total fat, fat $\%$ and fat free mass were $367 \pm 11.6 \mathrm{~g}, 26.9 \pm 4.8 \mathrm{~g}, 7.3 \% \pm 1.2 \%$ and $153.4 \pm$ 6.6 g respectively. Oral administration of EEB $\left(100,200,300 \mathrm{mg} \cdot \mathrm{kg}^{-1} \mathrm{BW}\right)$ for 42 days (from $15^{\text {th }}$ to $20^{\text {th }}$ week) considerably reduced body weight and body composition in a dose dependant manner. Among the three doses administered, EEB at a dose of $300 \mathrm{mg} \cdot \mathrm{kg}^{-1} \mathrm{BW}$, showed significant $(p<0.05)$ therapeutic effect. At 300 $\mathrm{mg} \cdot \mathrm{kg}^{-1} \mathrm{BW}$ of EEB, the body weight, total fat, fat \% and fat free mass were $387.1 \pm 6.7 \mathrm{~g}, 40.2 \pm 3.3 \mathrm{~g}, 10.97 \%$ $\pm 2.6 \%$ and $155 \pm 4.9$ g respectively.

\subsection{Estimation of Plasma Glucose, Insulin, Insulin Resistance}

The levels of plasma glucose, insulin and insulin resistance in control and experimental obese rats are shown in 


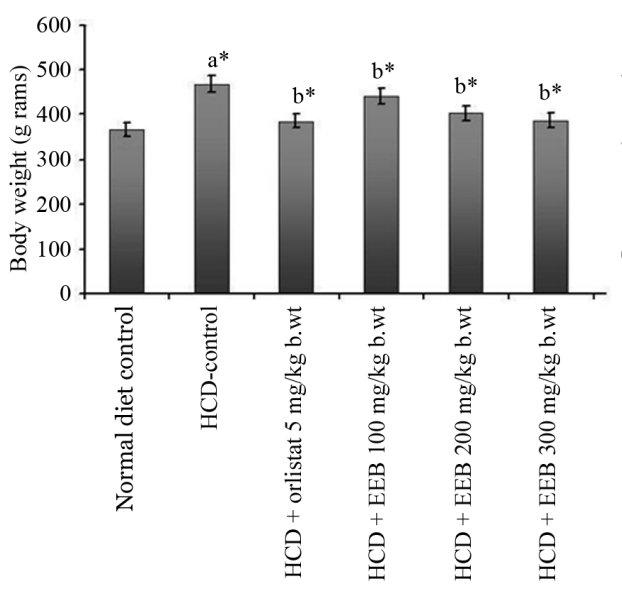

(a)

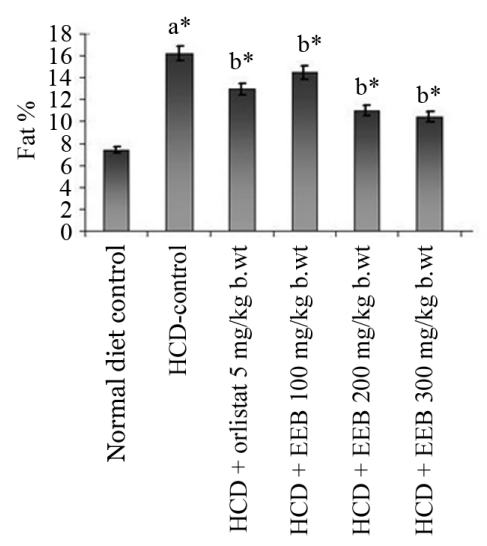

(g)

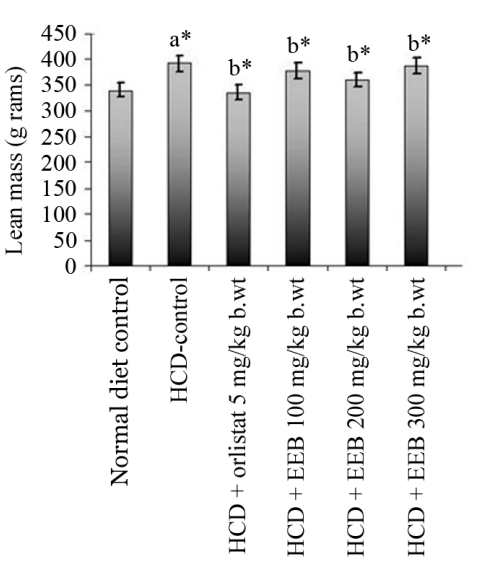

(b)

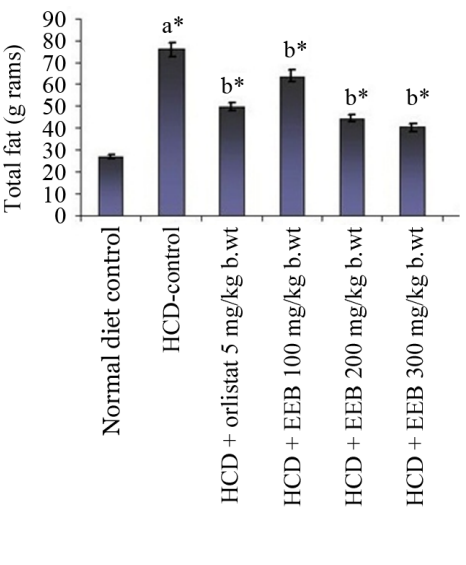

(c)

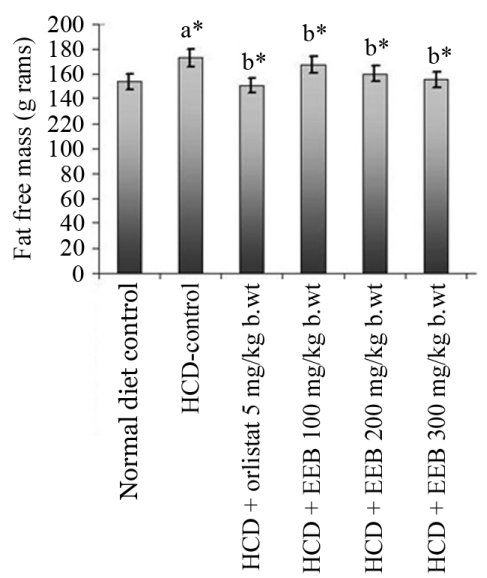

(h)

Figure 2. Effect of Bauhinia purpurea on body weight (Figure 1(a)); Lean mass (Figure 1(b)); Total fat (Figure 1(c)); Fat-\% (Figure 1(d)) and Fat free mass (Figure 1(e)) in normal and experimental obese rats Values are mean \pm S.D., $n=6$. Values are statistically significant at ${ }^{*} p<0.05$. a Significantly different from normal control; $\mathrm{b}^{*}$ Significantly different from HCD control.

Table 1. There was a significant $(p<0.05)$ elevation in plasma glucose, insulin and insulin resistance in HCD control obese rats when compared to normal control rats. Oral administration of different doses of EEB could bring these changes to near normalcy in a dose dependent manner, the most significant effect being observed at $300 \mathrm{mg} \cdot \mathrm{kg}^{-1} \mathrm{BW}$.

\subsection{Oral Glucose Tolerance Test}

Figure 3 depicts the results of oral glucose tolerance test performed on control and experimental obese rats. In the normal control group of rats, blood glucose level reached its maximum value at 60 min after glucose load and declined to near basal level at $120 \mathrm{~min}$, whereas, in HCD-induced obese rats, the peak increase in blood glucose level was noticed even after $60 \mathrm{~min}$ and remained high over the next $60 \mathrm{~min}$. Administration of EEB (300 $\mathrm{mg} \cdot \mathrm{kg}^{-1} \mathrm{BW}$ ) or orlistat to obese rats elicited a significant decrease in blood glucose level at $60 \mathrm{~min}$ and beyond when compared with HCD control rats.

\subsection{Leptin and Adiponectin Levels}

Leptin and adiponectin are two major adipocytokines of adipose tissue. Figure 4 explains the levels of leptin and adiponectin in control and experimental obese rats. There was a marked elevation in leptin and decrease in 
Table 1. Effect of EEB on plasma glucose, insulin and insulin resistance in normal and experimental obese rats.

\begin{tabular}{|c|c|c|c|}
\hline Groups & Glucose $\left(\mathrm{mg} \cdot \mathrm{dl}^{-1}\right)$ & Insulin $\left(\mu \mathrm{U} \cdot \mathrm{ml}^{-1}\right)$ & Insulin Resistance \\
\hline Control & $81.9 \pm 4.3$ & $5.5 \pm 0.7$ & $3.3 \pm 0.07$ \\
\hline HCD Control & $160.9 \pm 12.2^{\mathrm{a}^{* * * *}}$ & $14.8 \pm 1.5^{\mathrm{a}^{*}}$ & $5.3 \pm 1.6^{a^{*}}$ \\
\hline HCD + Orlistat & $128.5 \pm 13.1^{\mathrm{b} * * *}$ & $18.0 \pm 1.2^{\mathrm{b}^{*}}$ & $3.1 \pm 0.8^{\mathrm{b}^{*}}$ \\
\hline $\mathrm{HCD}+\mathrm{EEB}\left(100 \mathrm{mg} \cdot \mathrm{kg}^{-1} \mathrm{BW}\right)$ & $137.4 \pm 10.6^{\mathrm{b}^{* *}}$ & $15.4 \pm 1.9^{\mathrm{b}^{*}}$ & $4.4 \pm 1.2^{\mathrm{b}^{*}}$ \\
\hline $\mathrm{HCD}+\mathrm{EEB}\left(200 \mathrm{mg} \cdot \mathrm{kg}^{-1} \mathrm{BW}\right)$ & $132.1 \pm 2.6^{\mathrm{b}^{* *}}$ & $15.8 \pm 0.8^{\mathrm{b}^{*}}$ & $3.8 \pm 1.2^{\mathrm{b}^{*}}$ \\
\hline $\mathrm{HCD}+\mathrm{EEB}\left(300 \mathrm{mg} \cdot \mathrm{kg}^{-1} \mathrm{BW}\right)$ & $129.7 \pm 15.3^{\mathrm{b}^{* *}}$ & $16.6 \pm 0.7^{\mathrm{b}^{*}}$ & $3.2 \pm 0.6^{\mathrm{b}^{*}}$ \\
\hline
\end{tabular}

Values are mean \pm S.D., $\mathrm{n}=6$; Values are statistically significant at ${ }^{*} p<0.05,{ }^{* *} 0.01{ }^{* * *} 0.001 ;{ }^{\mathrm{a}}{ }^{*}$ Significantly different from control; ${ }^{\mathrm{b} *}$ Significantly different from HCD control.

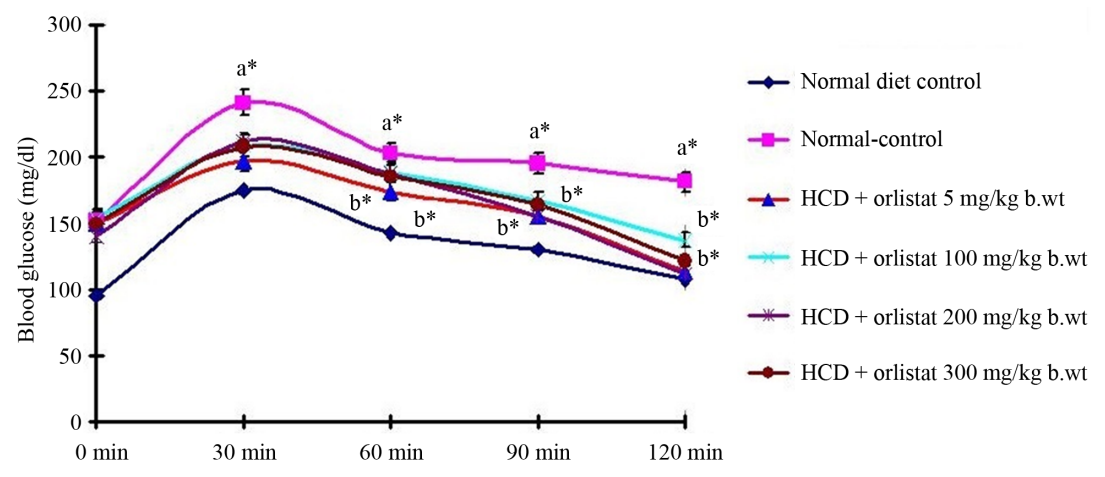

Figure 3. Effect of Bauhinia purpurea on glucose tolerance in control and experimental obese rats. Values are mean \pm S.D., $\mathrm{n}=6$. Values are statistically significant at ${ }^{*} p<0.05$. a ${ }^{*}$ Significantly different from normal control; $b^{*}$ Significantly different from HCD control.

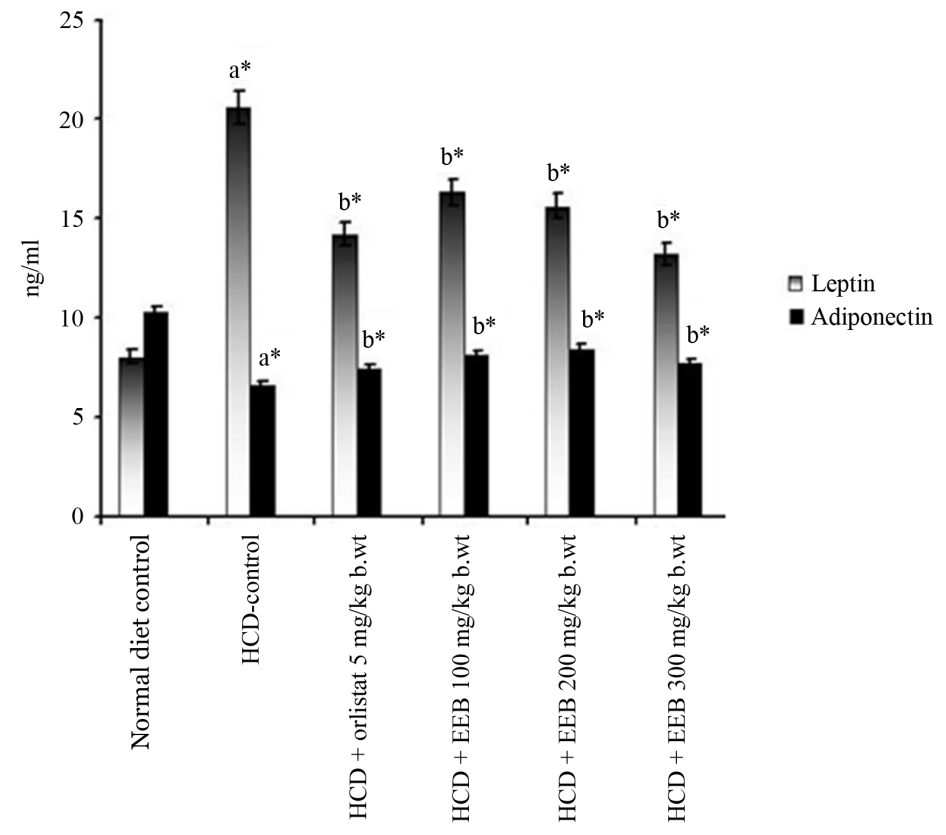

Figure 4. Effect of Bauhinia purpurea on leptin and adiponectin in control and experimental obese rats. Values are mean \pm S.D., $\mathrm{n}=6$. Values are statistically significant at ${ }^{*} p<0.05$. $\mathrm{a}^{*}$ Significantly different from normal control; $b *$ Significantly different from HCD control. 
adiponectin levels in HCD-fed obese rats over their normal control rats. Interestingly, treatment with EEB (300 $\left.\mathrm{mg} \cdot \mathrm{kg}^{-1} \mathrm{BW}\right)$ or orlistat has significantly $(p<0.05)$ restored their levels to normalcy.

\subsection{Assay of Amylase and Lipase}

The activities of amylase and pancreatic lipase of normal and experimental obese rats are exemplified in Figure 5. There was a two fold increase in the activities of lipase and amylase in HCD control rats when compared to normal control group of rats. Administration of EEB has brought down their activities in a dose dependant manner. A significant $(p<0.05)$ reduction in their activities was noted at $300 \mathrm{mg} \cdot \mathrm{kg}^{-1} \mathrm{BW}$ of EEB.

\subsection{Estimation of Lipid Profiles}

The levels of total cholesterol, FFAs, TGs, Phospholipids (PLs), HDL, LDL and VLDL were measured in plasma and are depicted in Figure 6(a). The concentrations of total cholesterol, FFAs, TGs, PLs, LDL and VLDL were markedly elevated while HDL level decreased in experimental obese rats as compared to the normal rats. Oral administration of EEB has reversed these alterations in a dose dependant manner, the most profound effect being noted at a dose of $300 \mathrm{mg} \cdot \mathrm{kg}^{-1} \mathrm{BW}$.

Liver tissue lipid profiles (total cholesterol, FFAs, TGs and PLs) of control and HCD-induced obese rats are shown in Figure 6(b). Supplementation of HCD, led to profound increase in tissue levels of total cholesterol, FFAs, TGs and PLs. Treatment with EEB $\left(300 \mathrm{mg} \cdot \mathrm{kg}^{-1} \mathrm{BW}\right)$ or orlistat significantly $(p<0.05)$ reduced liver tissue lipids in obese rats.

\section{Discussion}

Although there is a growing interest for herbal remedies across the globe, lack of adequate scientific evidences on plants and herbs is limiting their usage. Hence, more detailed herbal studies are needed on suitable animal models. The development of an ultimate animal model for obesity studies that would closely imitate the accepted metabolic features of human obesity is very exigent. Among the animal models of obesity, rats that are fed a high-calorie diet are proved to be suitable for testing antiobesity actions. In HCD-fed rats, we observed an increase in body weight and fat per cent, which is a hallmark of obesity. Long-term HCD feeding resulted in obesity which was linked with increased body weight, lean mass, total fat, fat percentage and fat free mass [15]. This might be due to consumption of a diet rich in calories in the form of sugars and fats and its accumulation in various parts of the body, leading to excessive growth of adipose tissue [16].

Oral administration of EEB significantly reduced body weight, lean mass, total fat, fat percentage and fat free mass in experimental rats, compared with that of HCD control rats. This suggests that EEB may inhibit lipid absorption, transportation and accumulation in adipose tissue by inhibiting fatty acid synthase, acetyl CoA carboxylase and other key enzymes involved in lipogenesis. These enzymes are regulated by SREBP-1c at the

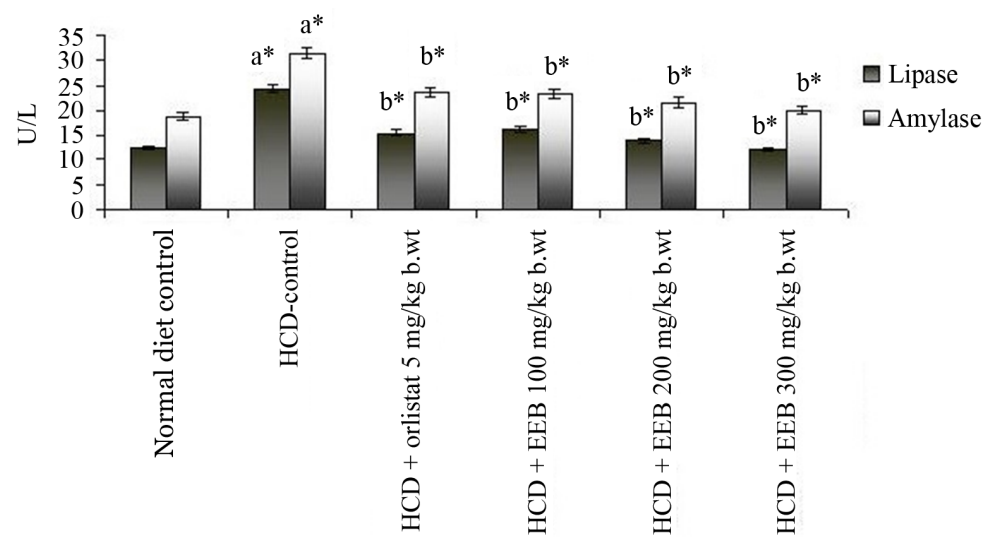

Figure 5. Effect of Bauhinia purpurea on lipase and amylase activities in control and experimental obese rats. Values are mean \pm S.D., $n=6$. Values are statistically significant at ${ }^{*} p<0.05$. a ${ }^{*}$ Significantly different from normal control; $\mathrm{b}^{*}$ Significantly different from HCD control. 


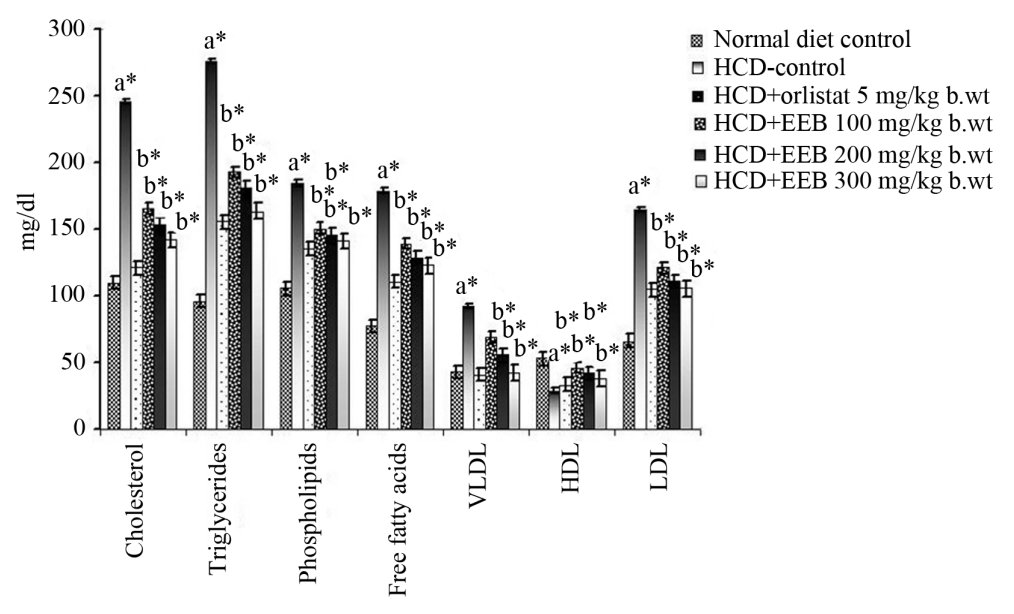

(a)

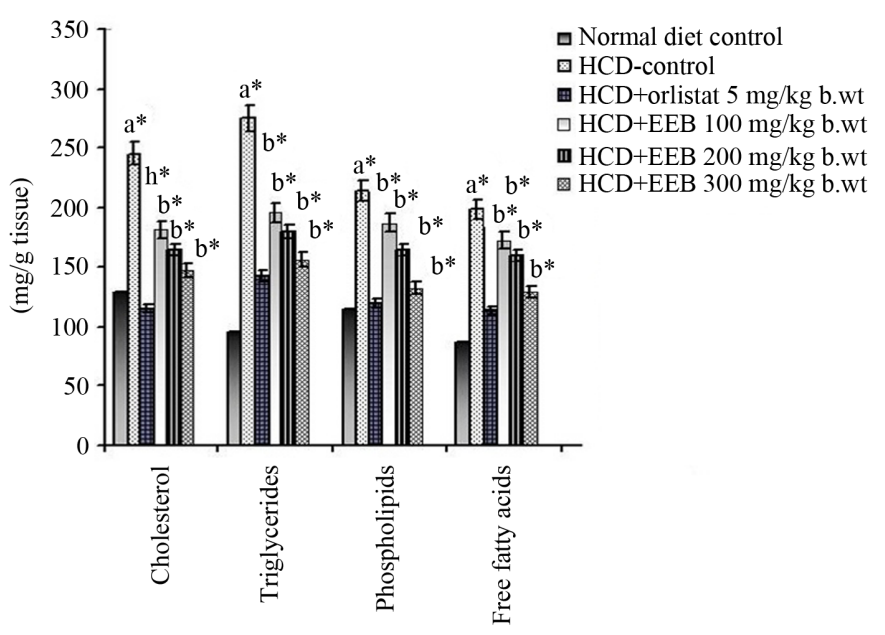

(b)

Figure 6. Effect of Bauhinia purpurea on plasma and tissue lipid profiles in normal and experimental obese rats. Values are mean \pm S.D., $n=6$. Values are statistically significant at ${ }^{*} p<0.05$. a Significantly different from normal control; $b^{*}$ Significantly different from HCD control.

transcriptional level [17]. The therapeutic effect of EEB could be due to the presence of bioactive compounds like bauhiniastatins, kaempferol (5,7,3,4-Tetramethoxyflavone) and related compounds in it. This is in agreement with Tomoko Akase et al. (2011) [18] who suggested that kaempferol, an active polymethoxyflavone found in Kaempferia parviflora reduced the accumulation of visceral fat in diet induced obese rats by escalating lipid metabolism through down regulation of SREBPs [19]. The antioxidant and anti hyperlipidemic activity of bauhiniastatins falls in line with the work of Pettit et al. (2005) [20] who reported the antioxidant, anti inflammatory and antineoplastic activity of bauniniastatins 1-4 in P388 lymphocytic leukemia cell line.

It is well known that insulin can indirectly inspire leptin secretion through its collective effects on the metabolism of nutrients, especially on glucose utilization in adipocytes. Thus, high calorie diet-induced obese rats tend to be an exceptional animal model to study molecular mechanisms for the development of obesity and insulin resistance. Cai-Jie et al. in their studies showed that feeding of HCD for a period of 12 weeks presented hyperglycemia, increased levels of plasma glucose, insulin and insulin resistance [21]. It is evident that longstanding exposure of animals to fed state leads to insulin resistance syndrome as was characterized by the amplified body weight, mild hyperglycemia and/or glucose intolerance, hypertriglyceridaemia. Insulin resistance and hyperglycemia are hallmarks of metabolic syndrome [22]. Insulin inhibits lipolysis which leads to impaired glucose-stimulated insulin secretion that is coupled with an inundate supply of lipids due to improved fat mobi- 
lization from adipose tissue [23]. HCDs have been shown to induce insulin resistance by different mechanisms but mainly considered through the Randle or glucose-fatty acid cycle [24]. In the present study, we observed increased plasma insulin level, and decreased insulin resistance with EEB treatment in the experimental rats. This was further supported by the HOMA-IR index, a method used to quantify insulin resistance and $\beta$-cell function, which showed decreased insulin resistance when EEB was administered. The observed effect could be due to kaempferol and bauhiniastatins, 2, 4 dihydroxy 4-methoxy dihydro chalcone and other compounds present in EEB causing hypoglycemic effect. This is in conformity with studies of Dmitry Govorko et al. (2007) [25] who reported glucose lowering activity of 2, 4 dihydroxy 4-methoxy dihydro chalcone through AMPK mediated path way in H4IIE hepatoma cell line.

Adipose tissue plays a major role in fat storage. Accumulation of excessive fat in adipocytes is the underlying phenomenon for obesity. Adipose tissue secretes adipokines (e.g. leptin, adiponectin, resistin, visfatin, tumour necrosis factor and interleukin-6) which play key roles in energy regulation [26]. Lower plasma adiponectin levels were observed in obese animals and it also showed a positive correlation with HDL-C [27]. Leptin, a circulating fat-derived protein produced by the adipose tissue plays a key role in appetite control and energy expenditure [28]. Its secretion is positively interrelated with the extent of triglyceride stores in adipocytes [29]. It is well known that obesity induces hyperleptinemia and hyperinsulinemia which are correlated with body weight and visceral fat. Reduction in body weight is possible by means of decrease in plasma leptin levels [30]. In the present study, significant elevation in plasma leptin level but a decrease in plasma adiponectin level was observed in HCD fed rats. Oral treatment with EEB considerably decreased leptin and increased adiponectin in plasma of HCD induced obese rats. Several polyphenols have been shown to exert therapeutic effect on lipid catabolism and decreasing insulin resistance which play essential roles in obesity [3]. Bauhinia purpurea might have ameliorated insulin resistance, through modulating lipid level in obese rats [31]. Bauhiniastatin and other compounds shown in LC-MS analysis may play important role in regulating obesity.

Amylase and lipase, the key enzymes of carbohydrate and lipid metabolism are used as targets for drug design in an attempt to treat several metabolic disorders including obesity. Now-a-days diet and natural sources have been used as amylase and pancreatic lipase inhibitors to hold back intestinal lipid absorption, which may contribute to reduced weight gain [32] [33]. Since dietary lipids and carbohydrates represent the major source of unwanted calories, the inhibition of fat and carbohydrates digestion is an interesting approach for reducing fat absorption. Inhibiting pancreatic lipase would facilitate fat non digestion and absorption and leading to lesser lipid intake. Lowered pancreatic amylase secretion reduced the absorption of carbohydrates by suppressing their digestion, leading to reduced energy intake [34]. A number of scientific reports depicted that $\alpha$-amylase inhibitors most of which are extracted from plants, can diminish the post-prandial hyperglycemia, thus regulating the abnormal glucose metabolism and prevention of metabolic disorder [35]. Oral supplementation of EEB inhibited the activity of pancreatic lipase and amylase in treated rats when compared with HCD control rats.

Dyslipidemic changes like elevated TGs, VLDL, total cholesterol, PLs, FFAs and LDL, and a declined plasma level of HDL have been observed in the present study upon HCD consumption. Our findings were supported by the work of Park et al. [36]. Thus, alteration of lipid profiles can be used as an index of obesity. There is an augmented discharge of FFA from adipose tissue to other tissues; mainly to the liver is possible during obesity and it may be due to the development of leptin resistance [37]. This leads to the development of fatty liver, decreases FFA oxidation which in turn increases the levels of hepatic and plasma triglycerides [38]. Excessive accumulation of TGs in the form of lipid stores is associated with a number of symptoms of metabolic syndrome [39]. The elevated level of phospholipids in the present study might be due to elevated levels of FFA and total cholesterol that could endorse the production of phospholipids. Prominent TC and elevated LDL levels intensify the risk of coronary heart disease [40]. On the other hand, high HDL is helpful in transporting surplus cholesterol to liver for excretion through bile [41]. Oral supplementation of EEB significantly lowered TC, TGs, FFAs and PLs in both plasma and liver and LDL levels in plasma of HCD-fed obese rats. Our finding are in line with Yongqi et al. (2009) who reported that supplementation of daidzein derivative from soy germ koji to fed animals led to hypolipidemic state by decreasing cholesterol absorption and secretion from the intestine [42] [43].

\section{Conclusion}

High caloric diet substantially increased the body weight, total fat, fat-\%, fat free mass and circulatory lipids in rats. Treatment with EEB has significantly alleviated HCD-induced obesity, hyperlipidemia and associated 
changes. The presence of phytoconstituents such as bauhiniastatins, kaempferol and related compounds, as revealed by LC-MS analysis, may play a prominent role in therapeutic activity of EEB. This study offers scientific validation to the traditional use of Bauhinia purpurea against several morbidities including hyperlipidemia. The precise mechanisms behind these beneficial effects of EEB need to be further investigated.

\section{Conflict of Interest Statement}

The authors declare that there are no conflicts of interest.

\section{Acknowledgements}

Authors are thankful to the University Grant Commission and Department of Biotechnology, New Delhi, India for financial assistance to carry out this work.

\section{References}

[1] World Health organization (WHO) (2011) Obesity and Overweight. Fact Sheet Number 311 (Updated February 2001). WHO, Geneva.

[2] Ramgopal, M., Kruthika, B.S., Surekha, D. and Meriga, B. (2014) Terminalia paniculata Bark Extract Attenuates Nonalcoholic Fatty Liver via Down Regulation of Fatty Acid Synthase in High Fat Diet Fed Obese Rats. Lipids Health Dis, 13, 58. http://dx.doi.org/10.1186/1476-511X-13-58

[3] Saravanan, G., Ponmuragan, P., Deepa, M.A. and Senthilkumar, B. (2014) Anti-Obesity Action of Gingerol: Effect on Lipid Profile, Insulin, Leptin, Amylase and Lipase in Male Obese Rats Induced by a High Fat Diet. Journal of the Science of Food and Agriculture.

[4] Ferranti, S. and Mozaffarian, D. (2008) The Perfect Storm: Obesity, Adipocyte Dysfunction, and Metabolic Consequences. Clinical Chemistry, 54, 6945-6955. http://dx.doi.org/10.1373/clinchem.2007.100156

[5] Colagiuri, S. (2010) Diabesity: Therapeutic Options. Diabetes, Obesity and Metabolism, 12, 463-473. http://dx.doi.org/10.1111/j.1463-1326.2009.01182.x

[6] Kishino, E., Ito, T., Fujita, K. and Kiuchi, Y.A. (2006) Mixture of the Salacia reticulate (Kotala himbutu) Aqueous Extract and Cyclodextrin Reduces the Accumulation of Visceral Fat Mass in Mice and Rats with High-Fat Diet-Induced Obesity. Journal of Nutrition, 136, 433-439.

[7] Boonphong, S., Puangsombat, P., Baramee, A., Mahidol, C., Ruchirawat, S. and Kittakoop, P. (2007) Bioactive Compounds from Bauhinia purpurea Possessing Antimalarial, Antimycobacterial, Antifungal, Anti-Inflammatory, and Cytotoxic Activities. Journal of Natural Products, 70, 795-801. http://dx.doi.org/10.1021/np070010e

[8] Ananth, K.V., Asad, M., Prem, K.N., Asdaqs, S.M.B. and Rao, G.S. (2010) Evaluation of Wound Healing Potential of Bauhinia purpurea Leaf Extracts in Rats. Indian Journal of Pharmaceutical Sciences, 72, 122-127. http://dx.doi.org/10.4103/0250-474X.62250

[9] Rajkapoor, B., Jayakar, B. and Murugesh, N. (2003) Antitumor Activity of Bauhinia variegata on Dalton’s Ascetic Lymphoma. Journal of Ethnopharmacology, 89, 107-109. http://dx.doi.org/10.1016/S0378-8741(03)00264-2

[10] Mali, R.G., Mahajan, S.G. and Mehta, A.A. (2007) Raktachandan (Bauhinia variegate): Chemistry, Traditional and Medicinal Uses-A Review. Pharmacognosy Revision, 1, 314-319.

[11] Shah, S.S., Gaurang, B. and Sabdeer, S.D. (2011) Effect of Piperine in the Regulation of Obesity-Induced Dyslipidemia in High Fat Diet Rats. Indian Journal of Pharmacology, 43, 296-299. http://dx.doi.org/10.4103/0253-7613.81516

[12] Mattews, D.R., Hosker, J.P., Rudenski, A.S., Naylor, B.A., Treacher, D.F. and Turner, R.C. (1985) Homeostasis Model Assessment: Insulin Resistance $\beta$-Cell Functions from Fasting Plasma Insulin Concentrations in Man. Diabetologia, 28, 412-419. http://dx.doi.org/10.1007/BF00280883

[13] Pittler, M.H. and Ernst, E. (2004) Dietary Supplements for Body-Weight Reduction: A Systematic Review. American Journal of Clinical Nutrition, 79, 529-536.

[14] Floch, J., Lee, M. and Stanley, G.H.S. (1957) A Simple Method for the Isolation and Purification of Total Lipids from Animal Tissues. Journal of Biological Chemistry, 226, 497-509.

[15] Bhandari, U., Chaudhari, H.S., Bisnoi, A.N., Kumar, V., Khanna, G. and Javed, K. (2013) Anti-Obesity Effect of Standardized Ethanol Extract of Embelia ribes in Murine Model of High Fat Diet-Induced Obesity. PharmaNutrition, 1, 50-57. http://dx.doi.org/10.1016/j.phanu.2013.01.001

[16] Oben, J., Kuate, D., Agbor, G., Momo, C. and Talla, X. (2006) The Use of a Cissus quadrangularis Formulation in the Management of Weight Loss and Metabolic Syndrome. Lipids in Health and Disease, 5, 24. 
http://dx.doi.org/10.1186/1476-511X-5-24

[17] Sato, R. (2010) Sterol Metabolism and SREBP Activation. Archives of Biochemistry and Biophysics, 501, $177-181$. http://dx.doi.org/10.1016/j.abb.2010.06.004

[18] Tomoko, A., Tsutomu, S. and Susumu, T. (2011) Antiobesity Effects of Kaempferia parviflora in Spontaneously Obese Type II Diabetic Mice. Journal of Natural Medicines, 65, 73-80. http://dx.doi.org/10.1007/s11418-010-0461-2

[19] Chang, C.J., Tzeng, T.F., Liou, S.S., Chang, Y.S. and Liu, I.M. (2011) Kaempferol Regulates the Lipid-Profile in High-Fat Diet-Fed Rats through an Increase in Hepatic PPAR $\alpha$ Levels. Planta Medica, 77, 1876-1882. http://dx.doi.org/10.1055/s-0031-1279992

[20] Pettit, G.R., Numata, A., Iwamoton, C., Usami, Y., Yamada, T., Ohishi, H.F. and Cragg, G.M. (2006) Antineoplastic Agents. 551. Isolation and Structures of Bauhiniastatins 1-4 from Bauhinia purpurea. Journal of Natural Products, 69, 323-327. http://dx.doi.org/10.1021/np058075+

[21] Zhou, C.J., Huang, S., Liu, J.Q., Qiu, S.Q., Xie, F.Y., Song, H.P., et al. (2013) Sweet Tea Leaves Extract Improves Leptin Resistance in Diet-Induced Obese Rats. Journal of Ethnopharmacology, 145, 386-392. http://dx.doi.org/10.1016/j.jep.2012.09.057

[22] Gregor, M.F. and Hotamisligil, G.S. (2011) Inflammatory Mechanisms in Obesity. Annual Reviews of Immunology, 29, 415-445. http://dx.doi.org/10.1146/annurev-immunol-031210-101322

[23] Saltiel, A.R. and Kahn, C.R. (2001) Insulin Signalling and the Regulation of Glucose and Lipid Metabolism. Nature, 414, 799-806. http://dx.doi.org/10.1038/414799a

[24] Randle, P.J., Garland, P.B., Hales, C.N. and Newsholme, E.A. (1963) The Glucose Fatty-Acid Cycle. Its Role in Insulin Sensitivity Andmetabolic Disturbances in Diabetes Mellitus. Lancet, 281,785-789. http://dx.doi.org/10.1016/S0140-6736(63)91500-9

[25] Govorko, D., Logendra, S., Wang, Y., Esposito, D., Komarnytsky, S., Ribnicky, D., Poulev, A., Wang, Z., Cefalu, W.T. and Raskin, I. (2007) Polyphenolic Compounds from Artemisia dracunculus L. Inhibit PEPCK Gene Expression and Gluconeogenesis in an H4IIE Hepatoma Cell Line. American Journal of Physiology, Endocrinology and Metabolism, 293, E1503-E1510. http://dx.doi.org/10.1152/ajpendo.00420.2007

[26] Garg, A. (2006) Adipose Tissue Dysfunction in Obesity and Lipodystrophy. Clinical Cornerstone, 8, S7-S13. http://dx.doi.org/10.1016/S1098-3597(06)80039-6

[27] Yang, W.S., Lee, W.J., Funahashi, T., Tanaka, S., Matsuzawa, Y., Chao, C.L., et al. (2001) Weight Reduction Increases Plasma Levels of an Adipose-Derived Anti-Inflammatory Protein, Adiponectin. The Journal of Clinical Endocrinology \& Metabolism, 86, 3815-3819. http://dx.doi.org/10.1210/jcem.86.8.7741

[28] Brennan, A.M. and Mantzoros, C.S. (2006) Drug Insight: The Role of Leptin in Human Physiology and Pathophysiology-Emerging Clinical Applications. Nature Reviews Endocrinology, 2, 318-327. http://dx.doi.org/10.1038/ncpendmet0196

[29] Staiger, H. and Haring, H.U. (2005) Adipocytokines: Fat-Derived Humoral Mediators of Metabolic Homeostasis. Experimental and Clinical Endocrinology \& Diabetes, 113, 67-79. http://dx.doi.org/10.1055/s-2004-830555

[30] Van Dielen, F.M., Veer, C., Buurman, W.A. and Greve, J.W.M. (2002) Leptin and Soluble Leptin Receptor Levels in Obese and Weight-Losing Individuals. Journal of Clinical Endocrinology \& Metabolism, 87, 1708-1716. http://dx.doi.org/10.1210/jcem.87.4.8381

[31] Lakshmi, B.V.S., Neelima, N., Kasthuri, N., Umarani, V. and Sudhakar, M. (2011) Antihyperlipidemic Activity of Bauhinia purpurea Extracts in Hypercholesterolemic Albino Rats. International Journal of PharmTech Research, 3, 1265-1272.

[32] Birari, R.B. and Bhutani, K.K. (2007) Pancreatic Lipase Inhibitions from Natural Sources: Unexplored Potential. Drug Discovery Today, 12, 879-889. http://dx.doi.org/10.1016/j.drudis.2007.07.024

[33] Nakajima, K., Muneyuki, T., Munakata, H. and Kakei, M. (2011) Revisiting the Cardiometabolic Relevance of Serum Amylase. BMC Research Notes, 4, 419. http://dx.doi.org/10.1186/1756-0500-4-419

[34] Tundis, R., Loizzo, M.R. and Menichini, F. (2010) Natural Products $\alpha$-Amylase and $\alpha$-Glucosidase Inhibitors and Their Hypoglycaemic Potential in the Treatment of Diabetes: An Update. Mini-Reviews in Medicinal Chemistry, 10, 315-331. http://dx.doi.org/10.2174/138955710791331007

[35] Layer, P., Rizza, R.A., Zinsmeister, A.R., Carlson, G.L. and DiMagno, E.P. (1986) Effect of a Purified Amylase Inhibitor on Carbohydrate Tolerance in Normal Subjects and Patients with Diabetes Mellitus. Mayo Clinic Proceedings, 61, 442-447. http://dx.doi.org/10.1016/S0025-6196(12)61978-8

[36] Park, Y., Storkson, J.M., Liu, W., Albright, J., Cook, M.E. and Pariza, M.W. (2004) Structure-Activity Relationship of Conjugated Linoleic Acid and Its Cognates in Inhibiting Heparin Releasable Lipoprotein Lipase and Glycerol Release from Fully Differentiated 3T3-L1 Adipocytes. Journal of Nutritional Biochemistry, 15, 561-569. 
http://dx.doi.org/10.1016/j.jnutbio.2004.04.004

[37] Torre, V.I., Tovar, A.R., Ramos, B.V.E., Cerbón, C.M.A. and Torres, N. (2008) Soy Protein Ameliorates Metabolic Abnormalities in Liver and Adipose Tissue of Rats Fed a High Fat Diet. Journal of Nutrition, 138, 462-468.

[38] Fungwe, T.V., Cagen, L.M., Cook, G.A., Wilcox, H.G. and Heimberg, M. (1993) Dietary Cholesterol Stimulated Hepatic Biosynthesis of Triglyceride and Reduces Oxidation of Fatty Acids in the Rat. Journal of Lipid Research, 34, 933-941.

[39] Lavie, C.J., Milani, R.V. and O’Keefe, J.H. (2011) Dyslipidemia Intervention in Metabolic Syndrome: Emphasis on Improving Lipids and Clinical Event Reduction. American Journal of the Medical Sciences, 341, 388-393. http://dx.doi.org/10.1097/MAJ.0b013e31821483fa

[40] Jin, D., Xu, Y., Mei, X., Meng, Q., Gao, Y., Li, B. and Tu, Y. (2013) Antiobesity and Lipid Lowering Effects of Theaflavins on High-Fat Diet Induced Obese Rats. Journal of Functional Foods, 5, 1142-1150. http://dx.doi.org/10.1016/j.jff.2013.03.011

[41] Garjani, A., Fathiazad, F., Zakheri, A., Akbari, N.A., Azarmie, Y., et al. (2009) The Effect of Total Extract of Securigera securidaca L. Seeds on Serum Lipid Profiles, Antioxidant Status, and Vascular Function in Hypercholesterolemic Rats. Journal of Ethnopharmacology, 126, 525-532. http://dx.doi.org/10.1016/j.jep.2009.09.003

[42] Guo, Y., Wu, G., Su, X., Yang, H. and Zhang, J. (2009) Antiobesity Action of a Daidzein Derivative on Male Obese Mice Induced by a High-Fat Diet. Nutrition Research, 29, 656-663. http://dx.doi.org/10.1016/j.nutres.2009.09.005

[43] Naidu, P.B., Nemani, H., Meriga, B., Mehar, S.K., Potana, S. and Ramgopalrao, S. (2014) Mitigating Efficacy of Piperine in the Physiological Derangements of High Fat Diet Induced Obesity in Sprague Dawley Rats. Chemico-Biological Interactions, 221, 42-51. http://dx.doi.org/10.1016/j.cbi.2014.07.008 
Scientific Research Publishing (SCIRP) is one of the largest Open Access journal publishers. It is currently publishing more than 200 open access, online, peer-reviewed journals covering a wide range of academic disciplines. SCIRP serves the worldwide academic communities and contributes to the progress and application of science with its publication.

Other selected journals from SCIRP are listed as below. Submit your manuscript to us via either submit@scirp.org or Online Submission Portal.
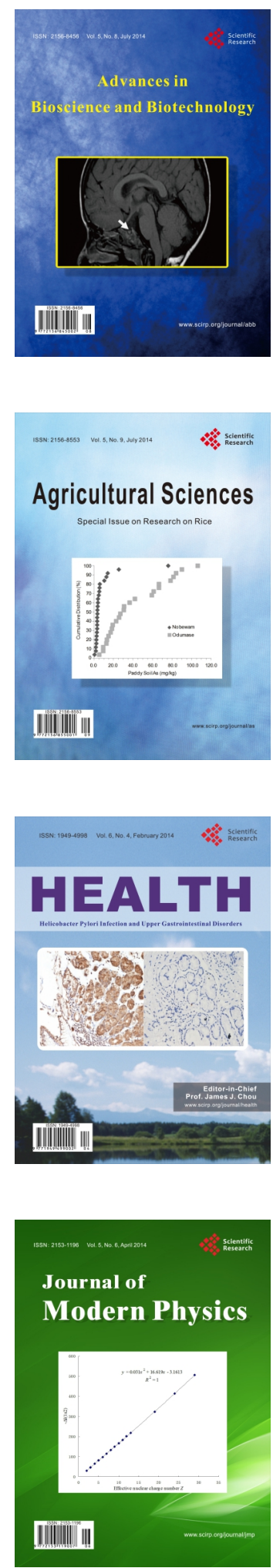
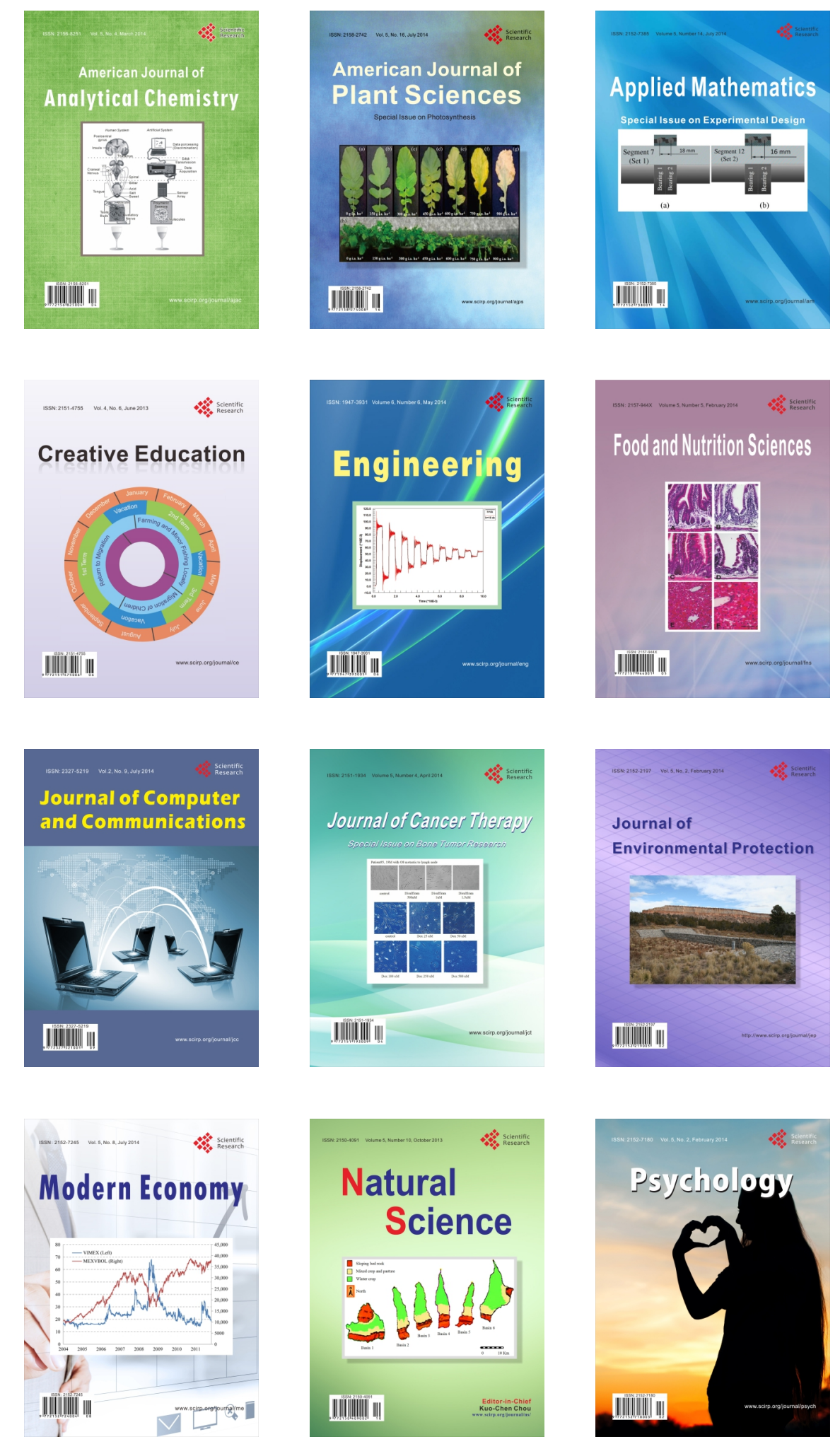